W. ST. C. SYMMERS, SEN.: SILICONE MASTITIS IN “TOPLESS" WAITRESSES

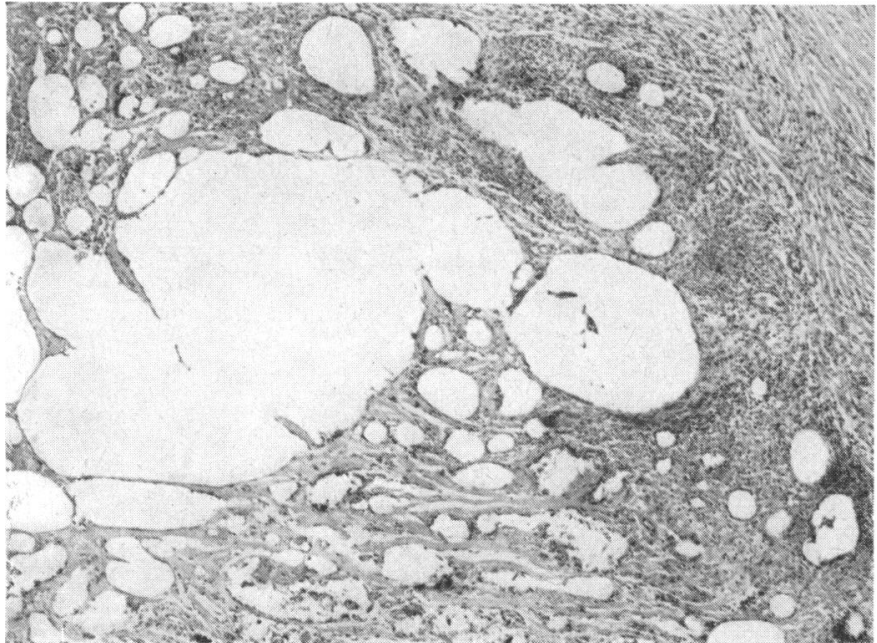

FIG. 1.-Case 1. Fibrosing granuloma of breast with histiocytosis and lymphocytosis associated with confluent spaces that had contained silicone fluid. (Haematoxylin-eosin. $\times 30$.)

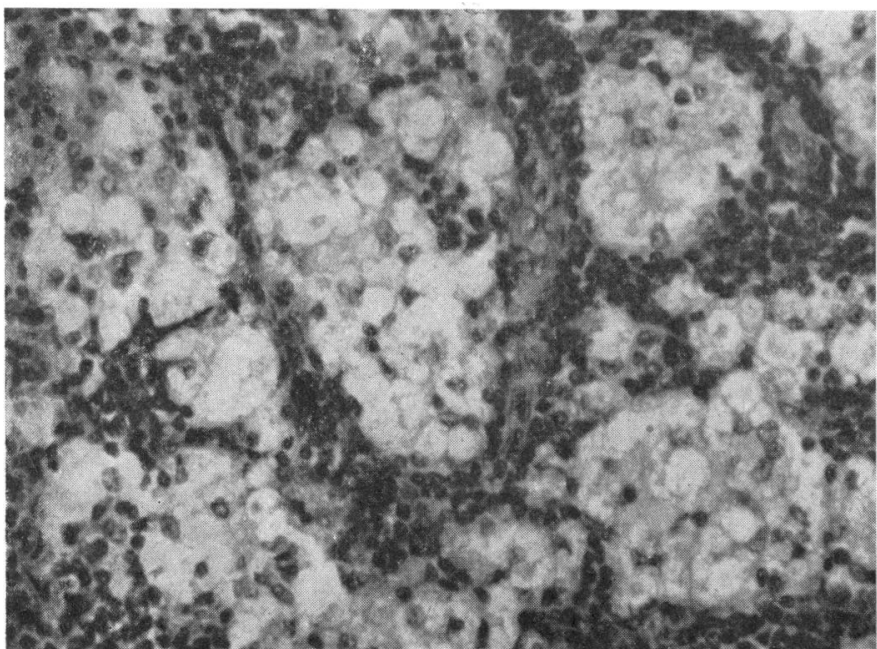

Fig. 3.-Case 1. Histiocytosis in an axillary lymph node. Compare with Fig. 4. (Haematoxylin-eosin. $\times 225$.)

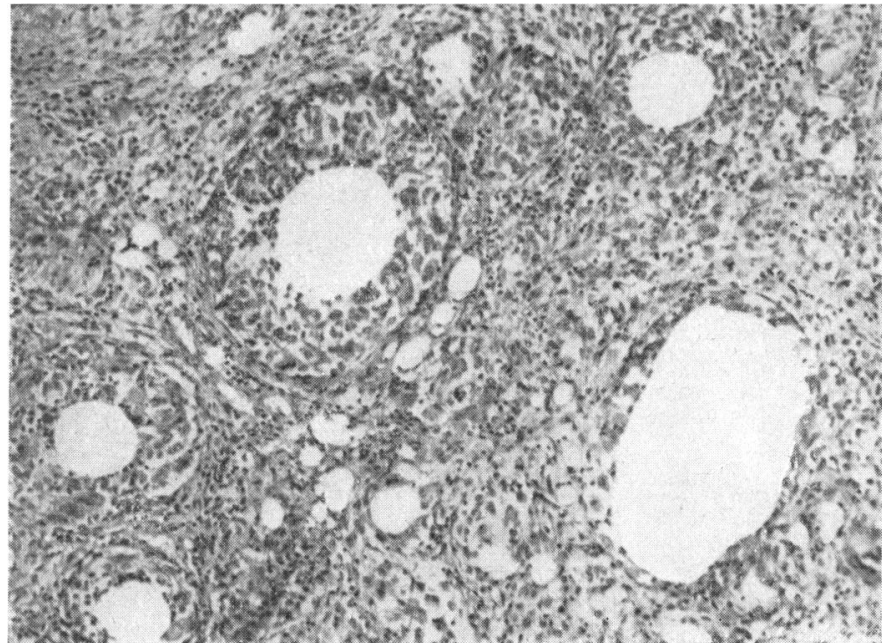

FIg. 2-Case 1. Tuberculoid and histiocytic reaction round spaces that had contained silicone fluid. The picture is identical with that of an oleogranuloma or paraffinoma. (Haematoxylin-eosin. $\times 90$.)

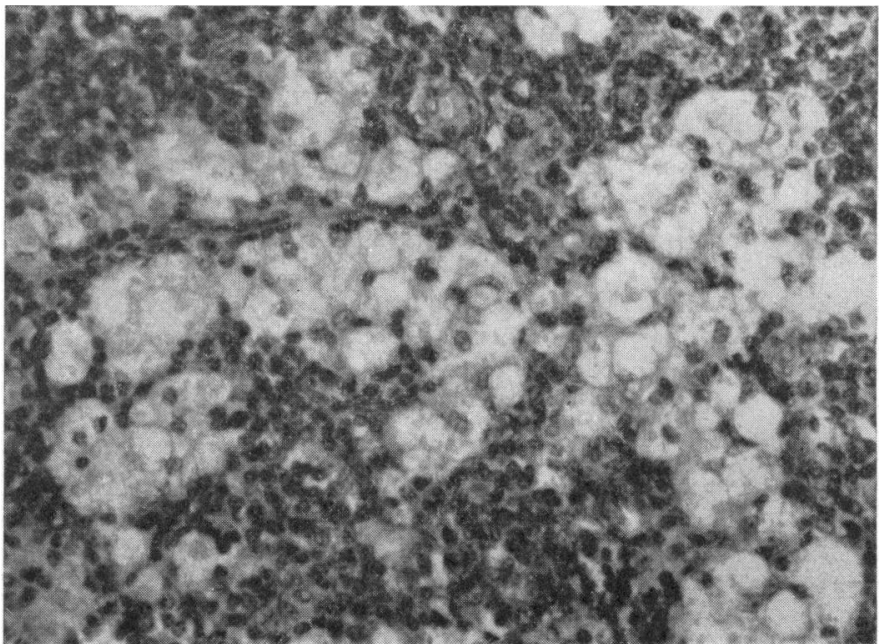

FIG. 4.-Leprous lymphadenitis for comparison with Fig. 3. The large pale cells are histiocytes: when stained by the Ziehl-Neelsen method they are shown to contain many lepra bacilli. (Biopsy from a Ugandan student working in London.) (Haematoxylin-eosin. $\times 225$.)

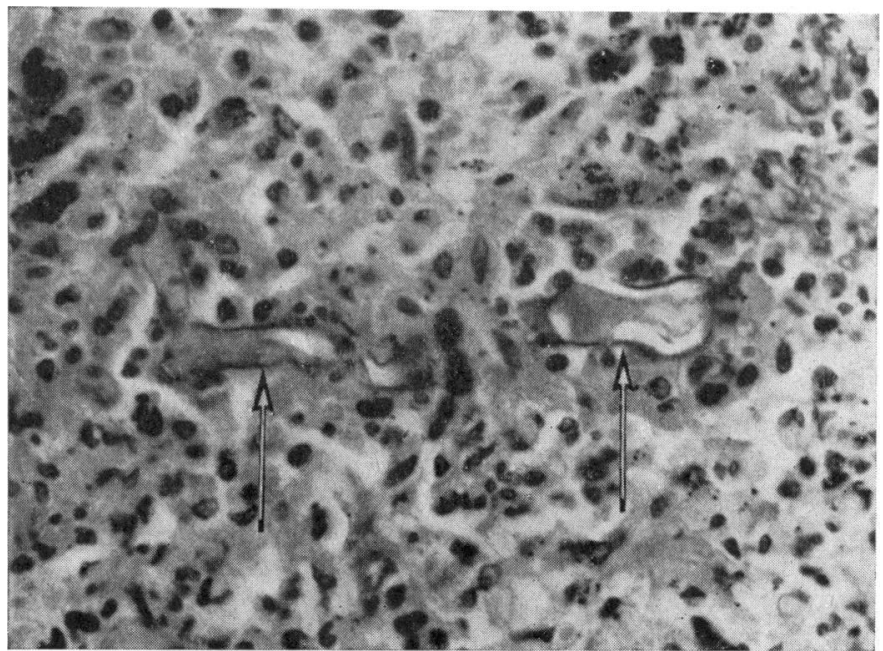

Fig. 6.-Case 3. Fungal infection of sinus in left breast. The arrows point to two pieces of hypha of the phycomycete. (Haematoxylin-eosin.

FIG. 5.-Case 2. Fibrosing lipogranulomatous reaction in a nodule from one breast. (Haematoxylin-eosin. $\times 70$.) 


\title{
Silicone Mastitis in "Topless" Waitresses \\ and Some Other Varieties of Foreign-body Mastitis
}

\author{
W. ST. C. SYMMERS,* SEN., M.D.
}

[With Spectal. plate facing page 9]

Brit. med. F., 1968, 3, 19-22

\begin{abstract}
Qummary: Three cases of disfiguring prosthetogenic $S$ mastitis are reported.

In two of the cases repeated injections of silicone fluid were followed by extensive bilateral granulomatous mastitis. The axilary lymph nodes were enlarged in both cases : in one of them a node was examined histologically and showed a remarkable proliferation of vacuolated histiocytes in the sinuses and medulla. Both patients had worked in "topless restaurants" and had been obliged to seek artificial means to maintain the excessively large bust that was necessary in that environment.

The third patient's mastitis followed implantation of polyethylene prostheses designed to be varied in bulk by injection or withdrawal of saline. A foreign-body reaction developed round the prostheses. In addition, a sinus developed in a needle track on one side ; this was accompanied by a local fungal and bacterial infection (Rhizopus species and Pseudomonas pyocyanea respectively).

The indications for introducing foreign maverials into the breasts to augment their size have to be weighed against the potential dangers that such procedures bring. The biological effects of injected silicones, particularly their long-term effects, are very imperfectly known. Statements implying that these compounds are harmless when injected are not correct. Among the hazards are (a) local sclerosing granulomatous reactions with permanent scarring, (b) histiocytosis secondary to carriage of silicones from their site of inoculation to regional lymph sodes and possibly to other parts of the lymphoreticular oystem, and, perhaps, (c) carcinogenic activity.
\end{abstract}

\section{Introduction}

Crosbie and Kaufman (1967) dealt with a case of bilateral oleogranulomatous mastitis following injection of melted petroleum jelly into the breasts as a means of augmenting their size. The case was remarkable in that the injections were made by the patient herself: she had read in the lay press about Japanese women procuring this procedure, and when a plastic surgeon whom she approached declined to operate on her "flat" chest she took matters into her own hands. Within a few months the result was a painful nodular mastitis, severe enough for bilateral mastectomy to be advised. This procedure the patient refused, permitting only local excision of affected tissue, with evacuation of as much jelly as could be expressed. Hers is but one more in the long sad series of records of foreignbody mastitis since women first sought means to enlarge their bosom beyond its natural dimensions.

Crosbie and Kaufman (1967) commented that it must be unusual to see oleogranuloma of the breast in Britain, whereas, they added, the condition is well recognized in the East. It is therefore worth noting that people who have travelled from Britain to the Far East have been known to submit themselves there to injection mammaplasty-often more from a sort of bravado than from any need to try to enlarge on natural attributes. The disfiguring consequences of a resulting mastitis are not likely to become evident until some time after the travellers have returned home. However, such patients account for only some of the cases of mammary oleogranulomas and other types of foreign-body mastitis that are seen in Britain, for the same procedures are carried out in Europe, whether for genuine medical reasons or on other grounds.

\section{Thirty-one Cases of Foreign-body Mastitis}

Through the interest and help of surgeons and pathologists in the British Isles I have been able to collect 31 unpublished cases of disfiguring foreign-body mastitis diagnosed here since 1946 and resulting from attempts to enlarge the breasts artificially. The materials that were identified in specimens from these cases included paraffin waxes, beeswax, silicone wax, silicone fluid, shellac, shredded oiled-silk fabric, silk tangle, glazier's putty, spun glass, and epoxy resin.

Most of these patients were not British. The mammaplasties had been carried out in the British Isles in only five cases; most of the other patients had been operated on in North America, the Orient, or north-western Europe. All but a few had been attended to under aseptic conditions by doctors or by skilled but medically unqualified cosmetologists; the rest had been in the hands of amateurs or of "back-street" operators.

\section{Some Current Procedures}

The safest procedure for enlarging the breasts so far devised seems to be transplantation into the retromammary space of adipose tissue from other parts of the patient's body. Even this may have serious complications through necrosis of the graft or infection.

Grafting operations are not readily available to women who have no clinical grounds for these measures. Moreover, to many women who would have a larger bust a cutting operation with its necessary stay in hospital has less appeal than achieving the same result by injections, particularly as the latter are likely to be less expensive. Injection methods provide the unorthodox or unethical operator with a technically simple procedure, theoretically suitable for consulting-room, office, or even salon use, but none the less fraught with risk to the patient and apt to cause her eventual disappointment, humiliation and distress, and sometimes danger.

\footnotetext{
* Histopathology Laboratory, Charing Cross Hospital Medical School,
London W.C.2
} 


\section{Mammaplasty by Injection of Silicone Fluid}

The needs of ethical surgery have long encouraged the search for a bland material that can be placed in human tissues safely and easily, with the object of altering outward appearances while avoiding undesirable effects, immediate or late. Successive foreign substances have been described over the years as meeting these requirements: without exception each has eventually proved unsatisfactory, even dangerously so. One of the latest of these substances is silicone fluid (dimethylpolysiloxane), ${ }^{1}$ which in pure form or mixed with other compounds has been injected into the tissues to act as a prosthesis.

Silicone fluid is commonly said to be biologically inert and therefore safe to use by injection (Wld Med., 1966). Such statements go farther than our present knowledge warrants ; for instance, Winer et al. (1964) and others have reported granuloma formation in human tissues after injection of silicone fluid. It is possible, of course, at least in some such cases, that the granulomatogenic factor is a constituent of proprietary, patent, or secret preparations of silicone fluid other than the silicone itself.

Reports of the action of silicone fluid on experimental animals are conflicting. Ballantyne et al. (1965) found it well tolerated in the subcutaneous tissue of guinea-pigs, rats, and mice, with little or no inflammatory response and no granuloma formation, even after injection of large amounts: "The volume injected far exceeded any conceivable clinical use." Nevertheless, these workers warned: "The injection of relatively large volumes of silicone in humans, such as for mammary augmentation, clearly poses more serious consideration for study than the use of small amounts for minor contour correction." They added: "Several important questions remain unsolved. The first and most important of these is whether or not absorption of appreciable amounts occurs, and, if so, what is the final distribution of absorbed material in the tissue systems ?" Ben-Hur (1967) has reported finding silicone in macrophages in regional lymph nodes after subcutaneous and intraperitoneal injections of silicone fluid into animals. He also found "siliconomas" in the viscera of animals six months after intraperitoneal administration of silicone fluid. Such observations indicate that this substance can be transported in the lymph stream from the site of inoculation to other parts, and they anticipate the finding of a conspicuous silicone lymphadenopathy in Case 1 in this paper (see below).

Various authors have raised the possibility that silicones may be carcinogenic. None of the published experimental observations can be regarded as unequivocally demonstrating the development of a malignant neoplasm. Growths described as fibrosarcomas were found by Russell et al. (1959) after implantation of silicone into rats; these and comparable observations by others are hard to assess from published accounts. It is pertinent to the difficulties of interpreting such findings that what Ben-Hur and Neuman (1963) originally took to be sweat-gland carcinomas occurring in 2 out of 36 mice that had been inoculated subcutaneously with silicone fluid were later thought to be spontaneous mammary carcinomas (Ben-Hur and Neuman, 1965). With so few data to go on, the most that may be said at present is that we have been warned of the possibility that silicones may be carcinogenic. So far, no association has been found between silicones and the development of human cancer. It may well be that clinical simulation of cancer of the breast by

Silicones are polymeric organosilicon compounds and are synthesized in various physical forms. They are extensively used in industry and they have also found various laboratory and clinical applications. Confusion in terminology has already resulted from the similarity in sound and spelling of silicone and silicon-typographical and proofsound and siliconoma, a name used by Sternber et al. (1964) and others to describe granulomas attributed to the $e t$ al. (1964) could as properly be applied to presence of silicone in the tissues, could as properly be applied to a lesion due to the prown to be of course, are well known to be granulomatogenic (causing, for in stance, the silicotic pneumoconioses and the post-traumatic silicotic granulomas (siliceous granulomas) of the skin). The name silicone granuloma, being less ambiguous than siliconoma, is preferable. a silicone granuloma, resulting in needlessly radical treatment, is a greater risk to the individual patient than the carcinogenic activity of silicone. Other foreign-body granulomas in the breast, particularly oleogranulomas (Symmers, 1955), have been mistaken for carcinomas and treated by radical mastectomy.

Slight as it seems to be up to the present, the evidence indicates that silicone fluid is not always as harmless to the tissues as its enthusiastic advocates would like. Two of the cases reported in this paper illustrate the extent and severity of the disfiguring granulomatous reaction that can follow its injection. Even if such results follow in only a minute proportion of those exposed to the risk the effects in these few are so grievous that the risk is not one to be taken for the sake of a cosmetic requirement. As things are, there are no figures on which to base any prediction of the incidence of undesirable effects of injections of silicone fluid, and we do not know in what circumstances such effects may be likely to appear. Those who ask for silicone injections and those who consider giving them should not let themselves be misled by such comments as, "Injection of silicone fluid is a safe, simple, and effective method of augmenting atrophied breast tissue" (Wld Med., 1966). The evidence now available contradicts this categorical statement.

\section{Case 1}

An Irishwoman aged 28 had worked for three years as a waitress in a "topless restaurant" (a restaurant where the waitresses work bare-breasted) in a North American resort. It was a condition of her employment that her bust should be thrusting and firm; to meet these requirements she attended a mastologist, who injected both breasts with silicone fluid. Although told that the injections would not have to be repeated she found that a noticeable reduction in the size of the breasts over several months made periodic "refills" necessary. About 18 months after the initial injections she began to notice increasing lumpiness of the breasts; at first this was evident only on palpation, but gradually the nodularity became visible. She also found that pain in the breasts was severer and lasted longer after the later injections and was accompanied by tenderness, and, transiently, by more enlargement than was intended; the subcutaneous veins of the breasts were conspicuous on these occasions and the skin blotchily reddened so that she had to take unusual care in order to obscure these blemishes with make-up. Painful enlargement of the axillary lymph nodes accompanied these symptoms: at first the lymphadenopathy was short-lasting, but eventually there was persistent lymph node enlargement. Several other waitresses had silicone injections from the same doctor, but the patient knew of only one who had ill-effects-this woman's reaction to the injections was similar to her own.

The patient returned to the British Isles and came to hospital for advice about the nodularity of her breasts. Both breasts were large and visibly nodular, with many tender foci of induration throughout their substance. There was distinct enlargement of the lymph nodes in both axillae. Two nodules in one breast, one in the other, and an axillary lymph node were excised.

Histology.-The three pieces of tissue from the breasts consisted entirely of sclerosing granuloma with a tuberculoid or histiocytic reaction round spaces that presumably had contained silicone fluid (Special Plate, Figs. 1 and 2). The picture was essentially the same as that of an oleogranuloma such as results from the presence of oily foreign substances in the tissues. However, in contrast to oleogranuloma there was an abundance of finely particulate, doubly refrate material in the interstices of the affected tissue and in the cytoplasm of the histiocytes, as described by Sternberg et al. (1964) in silicone granulomas in man and in animals. The doubly refractile material is assumed to be derived from the silicone fluid. Sections of the lymph node showed an unusual histiocytosis of the sinuses and medulla (Special Plate, Fig. 3). Doubly refractile material was present in the cytoplasm of many of the histiocytes. I have seen comparable histological changes in lymph nodes in certain lipidoses and in leprosy (Special Plate, Fig. 4), but without the doubly refractile material. There was no evidence of lipidosis or leprosy in this patient. 
Course.-The patient was last seen 18 months after the biopsy examination. Considerable disfigurement had resulted from shrinkage of scar tissue adherent to the skin and retromammary structures. The breasts were puckered and asymmetrical; the nipples were irregularly indrawn and noticeably different in level. A mass of firm nodules, each between 1 and $3 \mathrm{~cm}$. across, occupied both breasts.

\section{Case 2}

A teenage biology student, while on a study tour in Europe organized by her college, asked a London surgeon for a "top up." This turned out to mean replenishment injections of silicone fluid to restore her bust measurement before she returned to an annual vacation job as a "get-together girl " ${ }^{2}$ in a topless country club at home. She had first had silicone injections two years previously; these had increased her bust from 34 in. $(86 \mathrm{~cm}$.) to 37 in. $(94 \mathrm{~cm}$.) (her waist and hip measurements were respectively 23 in. $(58 \mathrm{~cm}$.$) and 34$ in. $(86 \mathrm{~cm}$.) and her height 63 in. $(160 \mathrm{~cm})$.$) .$ She said that the original mammaplasty had involved the injection over two to three weeks of about $400 \mathrm{ml}$. of Dow Corning 360 Medical, an ethical proprietary brand of pure silicone fluid. The revised contour was maintained for about four months; she then began to notice sagging of the breasts, with increasing fullness of the dependent part and development of some asymmetry. The sag and asymmetry were corrected by further injections of silicone fluid. The patient herself was convinced that some of the injected material must have been absorbed from the breasts. Restoration of the prominence and uplift necessary for her vacation work required substantial further injections of silicone fluid a year after the first mammaplasty. It was in the expectation of another such replenishment that she consulted the surgeon in London when on her way home from Europe.

Examination showed her breasts to be large, strikingly protrudent but tending to be pendulous, and slightly irregular in contour through puckering of the skin in a number of places. The nipples were indrawn and one was distinctly lower and more laterally placed than the other, apparently as a result of underlying fibrosis. The substance of the breasts was studded with rather tender, ill-defined nodules, ranging up to $3 \mathrm{~cm}$. in diameter. The lymph nodes on the medial wall of each axilla were large, firm, and tender.

During the examination it became clear that the patient was considerably worried that the nodularity of her breasts might be a sign of impending cancer. Two nodules were excised from each breast; the opportunity to examine an enlarged lymph node was not taken.

Histology.-Sections of the mammary nodules showed a sclerosing granuloma and associated fat necrosis (Special Plate, Fig. 5), with doubly refractile material in the interstitial space and in the cytoplasm of the histiocytes. The appearances did not differ significantly from those in Case 1.

Course.-The patient left England for her home a few days after the biopsy operation. She has not been in touch with us since, and her doctor has declined to give any information about her condition on the grounds that it would be a breach of a professional confidence to do so.

\section{Comment on Cases 1 and 2}

No material was kept for chemical analysis in either case. The paraffin blocks and most of the sections were lost in the laboratory of the silicone chemist, who had kindly agreed to try to determine whether silicone was indeed present, and no examination was carried out. The circumstantial evidence seems enough to incriminate the injections. The doctor who gave the injections to the first patient has provided limited information about the procedure; he has confirmed that the material was silicone fluid, but he has not answered questions about the further identity of the preparation and the amounts injected. It has not been possible to get in touch with the doctors who

${ }^{2}$ Hostess (sensu stricto) carried out the injections for the second patient; she herself was able to give the information that is included in the case history.

The histological picture in the breasts in both cases corresponds to that described by others in examples of silicone granuloma in man (Sternberg et al., 1964 ; Winer et al., 1964) and in animals (Ben-Hur and Neuman, 1965). The likeness to lipogranuloma, oleogranuloma, and paraffinoma was striking (see Special Plate, Figs. 1, 2, and 5), and even in the absence of a history of injections the microscopical findings should certainly have indicated the likelihood that foreign material was the cause of the reaction.

The unusual form of histiocytosis in the lymph node in Case 1 (Special Plate, Fig. 3) is presumed to be a specific response to silicone fluid carried in lymph from the breast. Its resemblance to the histiocytosis of some lipidoses and to the histiocytic form of leprous lymphadenitis (Special Plate, Fig. 4) (Desikan and Job, 1966) has been noted in the case report. The history and the appropriate additional histological investigations would enable these three conditions to be distinguished. The findings in the lymph node in Case 1 make it the more regrettable that there was no lymph node biopsy in Case 2.

Ben-Hur (1967) found that silicone fluid passes to the regional lymph nodes after subcutaneous or intraperitoneal inoculation in experimental animals. Such a process may in part explain the eventual decrease in size of the breasts in these two patients ; both had needed further injections of silicone to maintain the desired amplification of the bust. The recession was probably due in part also to the shrinkage of scar tissue associated with the chronic granulomatous process. It is pertinent to note that the tendency for fibrosis to follow silicone injections has even been referred to as an advantage of this form of mammaplasty, supposedly adding extra texture and firmness and thus better maintaining mammary contours. Unfortunately, the end-result of such fibrosis may be the nodulation that developed in these two patients.

An important aspect of the absorption of silicone through the lymph stream may be its ultimate fate and its possible effects on various systemic functions. We have virtually no knowledge yet of the long-term outcome of the presence of silicones in the human body, and particularly in the cells of the reticuloendothelial system. At least it seems to be clear that these substances are neither biologically inert nor harmless.

\section{Case 3}

An actress aged 22 was engaged to be married to a young surgeon. As her bust was small her fiancé persuaded her to allow a plastic colleague to implant a sealed polyethylene bladder behind each breast. This prosthesis was of an experimental type, designed with the intention that its effect could be finally determined by injecting or withdrawing saline solution once the patient had recovered completely from the implantation operation.

A few months after the operation on her breasts the patient was admitted to hospital with acute appendicitis. Appendicectomy was performed and convalescence was straightforward. It was observed at this time that there was a sinus in the left inframammary sulcus. The track of the sinus could be felt as a thick cord that merged into a zone of induration enclosing the periphery of the prosthesis, the edge of which was just palpable. A similar zone of induration surrounded the prosthesis in the right breast. It transpired that the patient or her fiancé had from time to time adjusted the amount of fluid in the prostheses: the sinus had formed in the site through which the left-hand prosthesis was usually needled.

The track of the sinus and its opening on the skin surface were excised. Histological examination showed the granulation tissue lining it to be infected by a phycomycetous fungus (Special Plate, Fig. 6).

The sinus re-formed some weeks later. Biopsy specimens again showed hyphae of the phycomycete, which cultures showed to be a 
opecies of Rhizopus. Pseudomonas pyocyanea was also grown from the exudate. The sinus was again excised, and this time the polyethylene prosthesis was removed from each breast at the patient's request. Histological examination of the fibrotic bed of each prosthesis showed sclerosing granulation tissue with many large multinucleate giant cells and conspicuous accumulations of macrophages. The fungal infection was present only on the left side and was confined to the sinus track and its immediate vicinity.

The prosthetectomy wounds healed quickly and permanently, leaving barely visible scars. The patient's engagement to be married was broken and she eventually married another man. They have had three children. Breast-feeding presented no problems.

\section{Comment on Case 3}

This case illustrates a foreseeable risk attending implantation of plastic prostheses. The possibility that the tissues of individual patients may react with inflammation and eventual fibrosis to the presence of supposedly inert materials has to be considered in relation to the particular therapeutic needs in each case. In the present case there was not only the bilateral inflammatory reaction to the prosthetic material itself, but, on one side, the added complication of infection resulting from the practice of needling the implanted bladders in order to vary the volume of their contents and so the size of the breasts.

My thanks are due to Mr. R. S. Barnett for his help with the photomicrography.

REPERENCES

Ballantyne, D. L., iun., Ree6, T. D., and Seidman, I. (1965). Plass. reconstr. Surg., 36, 330.

Ben-Hur, N. (1967). Wld Med. (Lond.), 2, No. 8, p. 13.

Ben-Hur, N., and Neuman, Z. (1963). Israel med. Y., 22, 15.

Ben-Hur, N., and Neuman, Z. (1965). Plast. reconstr. Surg., 36, 629.

Crosbie, R. B., and Kaufman, H. D. (1967). Brit. med. 7., 3, 840.

Desikan, K. V., and Job, C. K. (1966). Int. F. Leprosy, 34, 147.

Russell, F. E., Simmers, M. H., Hirst, A. E., and Pudenz, R. H. (1959) 7. nat. Cancer Inst., 23, 305.

Stemberg, T. H., Ashley, F. L., Winer, L. H., and Lehman, R. (1964) Houtarzt, 15, 281.

Symmers, W. St. C. (1955). Brit. med. 7., 2, 1536.

Winer, L. H., Sternberg, T. H., Lehman, R., and Ashley, F. L. (1964入 Arch. Derm., 90, 588.

Wld Med. (Lond.), 1966, 2, No. 6, p. 35.

\title{
Iron Absorption and Blood Loss in Patients with Hiatus Hernia
}

\author{
J. M. HOLT,* M.D., M.R.C.P. ; F. G. H. MAYET, + M.D. ; G. T. WARNER,* \\ S. T. CALLENDER,* M.D., F.R.C.P. ; A. J. GUNNING, † M.B., F.R.C.S., D.L.o.
}

Brit. med. F, 1968, 3, 22-25

Cummary : Iron absorption was measured in 28 patients, $\checkmark 19$ of whom were anaemic. The mean absorption in the anaemic patients was $39 \%$ and in the non-anaemic patients $8 \%$. Gastrointestinal blood loss was then measured in 26 of these patients. The mean estimated blood loss in the an zemic patients was $15 \mathrm{ml}$. a day and in the non-anaemic patients $3 \mathrm{ml}$. a day. In 16 of the 19 anaemic patients symptoms of anaemia were either the sole or the major complaint.

\section{Introduction}

Though an association between hiatus hernia and iron-deficiency anaemia has been recognized for many years, the precise cause of the anaemia is still disputed. This paper reports measurements of both iron absorption and blood loss in a group of patients with hiatus hernla and relates the findings to other features such as dyspepsia, oesophagitis, and the size and type of hernia.

\section{Material and Methods}

Twenty-eight patients with hiatus hernia were studied, 19 of whom had iron-deficiency anaemia for which no other cause

- Nuffield Department of Clinical Medicine, Radcliffe Infirmary, Oxford. t Nuffield Department of Surgery, Radcliffe Infirmary, Oxford

$\$$ Present address : Department of Medicine, University of Natal, Durban. could be found. In these the haemoglobin values ranged from 6.1 to $12 \mathrm{~g} . / 100 \mathrm{ml}$. and the M.C.H.C. from 24 to $31 \%$. In the remaining nine the lowest haemoglobin was $13 \mathrm{~g} . / 100 \mathrm{ml}$. and the lowest M.C.H.C. $33 \%$ (see Table I).

Iron absorption and blood loss were measured with the Oxford Whole Body Counter (Warner and Oliver, 1966 ; Callender et al., 1966 ; Holt et al., 1967. The subjects were given a standard oral dose of $5 \mathrm{mg}$. of ferrous iron labelled with about $5 \mu \mathrm{Ci}$ of ${ }^{59} \mathrm{Fe}$. The proportion of the dose retained 10 to 14 days later was taken as the amount which had been absorbed, though in iron-deficient subjects who incorporate ferrous iron rapidly into new cells this value would tend to give a slight underestimate of the actual amount absorbed if there were blood loss at that time. For the measurement of subsequent blood loss the whole-body count at 10 to 14 days after the oral dose was taken as the $100 \%$ level, and thereafter counts were made at intervals of two to three weeks for the next two to three months, as described previously (Holt et al., 1967). Blood loss at a rate greater than $4 \mathrm{ml}$./day was considered to be definitely abnormal.

In those subjects who showed less than $20 \%$ retention of the original oral dose a further 1.5 to $2 \mu \mathrm{Ci}$ of ${ }^{59} \mathrm{Fe}$ was given intravenously as ferric citrate. The beginning of the blood loss study was then delayed to allow incorporation of the ${ }^{59} \mathrm{Fe}$ into new red cells.

In two of the non-anaemic patients iron absorption alone was measured. In three anaemic patients a second measurement of blood loss was made after surgical repair of the hiatus hernia. 